\title{
WHILE STUDIES ON COVID-19 VACCINE IS ONGOING; THE PUBLIC'S THOUGHTS AND ATTITUDES TO THE FUTURE COVID-19 VACCINE
}

\author{
BÜŞRA AKARSU ${ }^{1}$, DİLARA CANBAY ÖZDEMİ ${ }^{1}$, Duygu AYHAN BASER ${ }^{1}$, Hilal \\ Aksoy $^{1}$, İzzet Fidanci ${ }^{2}$, and Mustafa Cankurtaran ${ }^{3}$ \\ ${ }^{1}$ Hacettepe University Faculty of Medicine \\ ${ }^{2}$ Affiliation not available \\ ${ }^{3}$ Hacettepe University
}

August 18, 2020

\begin{abstract}
OBJECTIVE In this study, we aim to investigate the thoughts and attitudes of individuals towards the future COVID-19 vaccine. METHODS This descriptive study was carried out on the web between 10/06/2020 - 10/07/2020. The sample constitutes all individuals above 18 years of age using social media and smartphone. The e-survey form was shared by the researchers via the web for a month, and those who completed the survey were included in the study and formed the sample of the research. RESULTS 759 were participated. $49.7 \%$ of the participants stated to be vaccinated; $38.4 \%$ of them stated to be vaccinated their children against COVID-19; if the vaccine for COVID-19 is developed. The request for the COVID 19 vaccine had relationship with gender, occupation, health insurance, anxiety level, having children, willing to get vaccinated for their children. "Afraid of the side effects of vaccine", "don't think it can be reliable as it will be a new vaccine" and "COVID-19 infection is a biological weapon and the vaccine will serve those who produce this virus" were the most common reasons for rejection of vaccine. CONCLUSION In our study afraid of the side effects of vaccine and not thinking it can be reliable as it will be a new vaccine is the most reasons of indecision and rejection about COVID 19 vaccine. In order for the future COVID 19 vaccination campaign to not fail, media, politicians, healthcare professionals should closely follow the vaccination development processes, inform the public transparently and consider public's concerns.
\end{abstract}

\section{Hosted file}

manuscript a\selectlanguage\{polish\}şı \selectlanguage\{english\}covid.docx available https://authorea.com/users/351984/articles/476379-while-studies-on-covid-19-vaccineis-ongo $\mathrm{i} \% \mathrm{CC} \% 87 \mathrm{ng}$-the-public-s-thoughts-and-attitudes-to-the-future-covid-19-vaccine

\section{Hosted file}

tables aşı.docx available at https://authorea.com/users/351984/articles/476379-while-studieson-covid-19-vaccine-is-ongoi\%CC\%87ng-the-public-s-thoughts-and-attitudes-to-the-futurecovid-19-vaccine 